\title{
Metabolismo de plantas Epidendrum fulgens em fase de enraizamento e de aclimatização ex vitro ${ }^{(1)}$
}

\author{
RAFAELLEN CAROLINE STORCK ${ }^{(2)}$ E GILMAR ROBERTO ZAFFARI ${ }^{(3)}$
}

\begin{abstract}
Resumo
A composição dos meios de cultivo durante a fase de enraizamento in vitro está diretamente relacionada ao sucesso da aclimatização. Pré-tratamentos com baixas concentrações de carboidratos e de sais no meio de enraizamento têm estimulado uma pré-adaptação à condição autotrófica. Plântulas de Epidendrum fulgens foram cultivadas na fase de enraizamento em diferentes concentrações salinas do meio de MS e de sacarose, adicionados ou não de reguladores de crescimento, durante 60 dias, com objetivo de promover uma pré-adaptação à condição autotrófica da fase de aclimatização. A redução de 50\% na concentração salina do meio MS adicionado de $1,5 \%$ e de 3,0\% (p/v) de sacarose, e de $67 \%$ com $1,5 \%$ de sacarose nos meios de cultivo, com ou sem regulador de crescimento, promoveu aumento significativo na altura das plântulas de Epidendrum fulgens. Entretanto, o mesmo efeito não foi verificado no número de raízes. As plântulas cultivadas em meio de cultura com redução na concentração de nutrientes e de sacarose, adicionado ou não de reguladores de crescimento tiveram um metabolismo mixotrófico ao final dos 60 dias de enraizamento in vitro e uma maior autotrofia das plântulas aos 15 dias de aclimatização.
\end{abstract}

Palavras-chave: orquídea, pré-aclimatização, cultura de tecidos.

\section{Abstract \\ Metabolism of Epidendrum fulgens during rooting and ex-vitro acclimatization}

The culture media composition during the in vitro rooting phase is directly related to the success of acclimatization. Pre-treatments using low carbohydrate and salt concentrations in the rooting medium have stimulated a pre-adaptation to an autotrophic conditions. Epidendrum fulgens plantlets were cultivated, for 60 days, in different salt concentrations of MS and sucrose medium with or without growth regulators, during the rooting phase. This treatment aimed to promote a pre-adaptation to an autotrophic condition during the acclimatization stage. A $50 \%$ reduction in the salt concentration of MS medium, added to $1.5 \%$ and $3.0 \%(\mathrm{w} / \mathrm{v})$ sucrose, and a $67 \%$ reduction in the salt concentration added to $1.5 \%$ sucrose in the culture media, with or without growth regulator, promoted a significant increase in the plantlets height. However, the same effect was not observed in the root numbers. Plantlet cultivated in the medium where nutrient and sucrose concentrations were reduced, with or without growth regulators, presented a mixotrophic at the end of the 60 day in vitro rooting period and a greater autotrophy of the plantlet at 15 days of acclimatization.

Key words: Orchid, pre-acclimatization, tissue culture.

\section{INTRODUÇÃO}

A qualidade fisiológica dos tecidos vegetais cultivados in vitro é um dos principais fatores responsáveis pelo bom desempenho das plantas durante o transplantio (VAN HUYLENBROCK e DEBERGH, 2000). O principal fator da vulnerabilidade durante a fase de aclimatização é o reduzido desenvolvimento do aparato fotossintético in vitro (GROUT e ASTON, 1977). Desse modo, o controle do ambiente in vitro se apresenta como uma estratégia fundamental e de crescente importância na promoção do crescimento, desenvolvimento e morfologia de plantas in vitro (KOZAI e NGUYEN, 2003). A presença de sacarose no meio de cultura inibe especificamente a formação de clorofila e a atividade fotossintética, inibindo ou reduzindo o crescimento autotrófico (GEORGE, 1996; KOZAI e KUBOTA, 2001). Ao estudarem a micropropagação de diversas espécies, KOZAI e NGUYEN (2003) verificaram que para promover a fotossíntese, a transpiração e o acúmulo de matéria seca em plantas cultivadas in vitro, em meio de cultura sem sacarose, é necessário aumentar a intensidade luminosa e a difusão de $\mathrm{CO}_{2}$ e a umidade relativa em volta da planta.

Outro fator responsável pela alta taxa de mortalidade das plântulas durante a aclimatização é o estresse hídrico. Explantes cultivados sob regime heterotrófico originam plantas com elevado conteúdo de água, com grande risco de desidratação e morte durante a aclimatização (KUBOTAe KOZAI, 1992).

\footnotetext{
${ }^{(1)}$ Recebido para publicação em 20/12/06 e aceito para publicação em 23/0807.

(2) Bióloga, UNIVALI/CTTMar, Laboratório de Cultivo Celular - Caixa Postal 360, CEP: 088.302-202, Itajaí (SC), Brasil.

(3) Eng. Agrônomo, Dr., UNIVALI e Estação Experimental de Itajaí (Epagri), Caixa Postal 277, CEP: 88301-970, Itajaí, (SC).
} 
Essa transferência da fase heterotrófica, em que a planta dispõe de um suprimento externo de energia, para um estado autotrófico, no qual precisa realizar a fotossíntese e incrementar a absorção de sais é essencial na adaptação das plantas à nova condição ambiental (GRATTAPAGLIA e MACHADO, 1998). Pré-tratamentos de redução da condição heterotrófica podem ser aplicados para aumentar a sobrevivência das plantas no transplantio. Para isso pode-se reduzir a concentração de carboidratos e de sais no meio de enraizamento estimulando uma préadaptação à condição autotrófica (TORRES et. al., 1998).

A espécie Epidendrum fulgens, orquídea de hábito terrestre, planta ornamental e medicinal, tem tido sua população cada vez mais reduzida, provocando a degradação do paisagismo de nossas praias, devido ao desmatamento litorâneo e a coleta desordenada para comércio e ornamentação. O presente trabalho objetivou estudar os aspectos fisiológicos e bioquímicos do metabolismo de plantas de Epidendrum fulgens durante a fase in vitro e ex vitro, visando otimizar o processo de aclimatização.

\section{MATERIALEMÉTODOS}

O material vegetal consistiu de propágulos de Epidendrum fulgens (Brongn) provenientes da fase de multiplicação em meio Knudson C modificado (1946) submetidas à fase de enraizamento in vitro em meio MS (MURASHIGE e SKOOG, 1962). Os meios de cultura utilizados consistiram em variações da concentração salina de MS e, suplementados com 1,0mg L ${ }^{-1}$ de tiamina. $\mathrm{HCl}$ e 1,0mg $\mathrm{L}^{-1}$ de mio-inositol, variando a concentração de sacarose em 1,5\% e 3,0\% (p/v) e 0,6\% (p/v) de ágar (Merse). Os reguladores de crescimento (RC), adicionados ao meio de cultura, foram o ácido -naftaleno acético (ANA) na concentração de $0,02 \mathrm{mg} \mathrm{L}^{-1}$ e ácido giberélico $\left(\mathrm{GA}_{3}\right)$ na concentração de $0,01 \mathrm{mg} \mathrm{L}^{-1}$. O pH do meio de cultura foi ajustado para 5,7 antes da autoclavagem. Frascos de cultura de $100 \mathrm{~mL}$ com $20 \mathrm{~mL}$ de meio, vedados com tampa plástica transparente, contendo um explante cada, foram mantidos em câmara de crescimento com 16 horas de luz a $50 \mu \mathrm{mol} \mathrm{m}^{-2} . \mathrm{s}^{-1}$, em temperatura de $27 \pm 2^{\circ} \mathrm{C}$, durante 60 dias.
As plântulas foram submetidas aos seguintes tratamentos: T1= MS 33\% e 1,5\% sacarose sem RC; T2 = MS 33\% e 3,0\% sacarose sem RC; T3 = MS 50\% e 1,5\% sacarose sem RC; T4 = MS 50\% e 3,0\% sacarose sem RC; T5 $=$ MS 33\% e 1,5\% sacarose com RC; T6 = MS 33\% e $3,0 \%$ sacarose com RC; T7 $=$ MS 50\% e 1,5\% sacarose com RC; e T8 = MS 50\% e 3,0\% sacarose com RC. A aclimatização das plantas foi realizada considerando-se a concentração de sacarose, $1,5 \%$ e $3,0 \%$, presente no meio de cultura durante a fase de enraizamento.

As análises bioquímicas foram realizadas aos 60 dias do cultivo in vitro e aos 15 dias da fase de aclimatização. A extração de proteínas foi realizada a partir de $50 \mathrm{mg}$ de massa seca da planta inteira pelo método de RANDI e FELIPPE (1988) e a dosagem foi realizada pelo método de BRADFORD (1976). Os açúcares solúveis totais e o amido foram extraídos a partir da metodologia descrita por SHANNON (1968) e McCREADY et al. (1950), respectivamente, a partir de $50 \mathrm{mg}$ de massa seca da planta inteira e dosados pelo método de UMBREIT e BURRIS (1964). A determinação de pigmentos foi realizada a partir do método colorimétrico descrito por LICHTENTHALER (1987), utilizando uma planta sem raízes, e de ceras epicuticulares a partir de duas folhas por planta pelo método de ROBERTS et al. (1990).

\section{RESULTADOS E DISCUSSÃO}

A redução da concentração salina do meio MS em $50 \%$ e $67 \%$ e a adição de $3,0 \%$ de sacarose nos meios de cultivo promoveram aumento significativo na altura das plantas de Epidendrun fulgens, aos 60 dias de cultivo (Tabela 1). Entretanto, o mesmo efeito não foi verificado no número de raízes. Os meios de cultura utilizados para enraizamento são caracterizados, de um modo geral, pela redução na concentração de sais (McCOMB e BENNETT, 1985). O resultado obtido por CENTELLAS et al. (1999), em plantas de Malus domestica, demonstra que a concentração de MS 50\% promoveu diferença significativa no número de raízes independente do regulador de crescimento (RC) testado. Porém, CALVETE et al. (2002) demonstraram em plantas de morango que a adição de $1,5 \%$ ou $3,0 \%$ de sacarose ao meio de cultura, não promoveu dife-

Tabela 1. Crescimento das plantas de Epidendrun fulgens em meio MS adicionado ou não de reguladores de crescimento (RC), durante a fase de enraizamento in vitro, após 60 dias de cultivo $(\mathrm{n}=7)$

Table 1. Plant growth of Epidendrun fulgens in MS medium with or without growth regulators (GR) addition during an in vitro rooting, after 60 days of growth period $(n=7)$

\begin{tabular}{|c|c|c|c|c|}
\hline \multirow{3}{*}{ TRATAMENTO } & \multicolumn{2}{|c|}{ ALTURA $(\mathrm{CM})$} & \multicolumn{2}{|c|}{ NÚMERO DE RAÍZES } \\
\hline & \multicolumn{2}{|c|}{ TEMPO (DIAS) } & \multicolumn{2}{|c|}{ TEMPO (DIAS) } \\
\hline & 0 & 60 & 0 & 60 \\
\hline T1 (MS 33\% 1,5\% SACAROSE S/RC) & 1,83 & $3,64 \mathrm{ABC}$ & 2,82 & $5,30 \mathrm{NS}$ \\
\hline T2 (MS 33\% 3,0\% SACAROSE S/RC) & 1,83 & $2,61 \mathrm{C}$ & 2,82 & $5,28 \mathrm{NS}$ \\
\hline T3 (MS 50\% 1,5\% SACAROSE S/RC) & 1,83 & $4,62 \mathrm{~A}$ & 2,82 & $5,34 \mathrm{NS}$ \\
\hline T4 (MS 50\% 3,0\% SACAROSE S/RC) & 1,83 & $3,75 \mathrm{ABC}$ & 2,82 & $4,57 \mathrm{NS}$ \\
\hline T5 (MS 33\% 1,5\% SACAROSE C/RC) & 1,83 & $4,78 \mathrm{~A}$ & 2,82 & 4,99 NS \\
\hline T6 (MS 33\% 3,0\% SACAROSE C/RC) & 1,83 & $3,02 \mathrm{BC}$ & 2,82 & $3,85 \mathrm{NS}$ \\
\hline T7 (MS 50\% 1,5\% SACAROSE C/RC) & 1,83 & $4,44 \mathrm{AB}$ & 2,82 & 4,48 NS \\
\hline T8 (MS 50\% 3,0\% SACAROSE C/RC) & 1,83 & $5,09 \mathrm{~A}$ & 2,82 & $4,31 \mathrm{NS}$ \\
\hline
\end{tabular}

As médias seguidas da mesma letra na coluna não diferem entre si pelo teste de tukey $(\mathrm{p}<0,05)$,

$\mathrm{ns}=$ valores não significativos pelo teste de tukey $(\mathrm{p}<0,05)$ 
renças significativas na produção de biomassa das raízes.

O metabolismo das plantas na fase in vitro, quando submetidas a concentrações salinas reduzidas do meio MS, combinadas com $1,5 \%$ e $3,0 \%$ de sacarose, na presença ou ausência de RC, mostrou-se alterado depois de 60 dias de cultivo. A permanência de E. fulgens durante 60 dias no meio de enraizamento in vitro promoveu aumento nos teores de clorofila total e de proteínas totais (Tabela 2).

O tratamento MS 33\% e 1,5\% de sacarose promoveu maior teor de clorofila total nas plantas, seguido dos tratamentos MS 33\% e 3,0\% de sacarose sem RC e MS $50 \%$ e 3,0\% de sacarose sem RC. Contudo, pode-se observar que os tratamentos contendo RC influenciaram negativamente a biossíntese de clorofila total. Porém, de um modo geral a presença de $\mathrm{RC}$ nos meios de cultura, induziu maior teor de proteínas totais nas plantas de E. fulgens (tabela 2).

A composição e a concentração dos RC são fatores determinantes no crescimento e no padrão de desenvolvimento na maioria das culturas in vitro. As auxinas podem contribuir para as respostas observadas in vitro uma vez que seu efeito depende da sua estabilidade no meio e de seu metabolismo pela célula (TORRES e CALDAS, 1998; CHEN, 2001; SOUZA et al. 2003; LEYSER, 1999), onde os tratamentos contendo RC no presente trabalho apresentaram maiores teores de proteínas.
O cultivo das plantas no meio MS 50\% e 1,5\% de sacarose com regulador de crescimento promoveu os maiores teores de açúcares solúveis totais e de amido, em relação aos demais tratamentos (Tabela 3). Ao comparar os teores de açúcares solúveis totais das folhas de E. fulgens com os de amido, observou-se, em todos os tratamentos, uma relação inversa. Esse fato ocorre porque a biossíntese de sacarose e amido é iniciada a partir do ciclo de Calvin e são reações competitivas, em que a síntese de amido ocorre nos cloroplastos e a da glicose no citosol. Apesar da compartimentalização dos locais de síntese, ocorre comunicação entre eles e a síntese de um inibe a síntese do outro (TAIZ e ZEIGER, 2004).

O suprimento de concentrações de $33 \%$ do meio MS, aliado a $1,5 \%$ ou de $3,0 \%$ de sacarose, na ausência de $\mathrm{RC}$, resultou em maior biossíntese e deposição de ceras epicuticulares nas folhas das plantas, após 60 dias de cultivo (tabela 3 ).

O cultivo de plantas de E. fulgens durante a fase de enraizamento in vitro em meio de cultura contendo no máximo $50 \%$ da concentração de sais do meio MS, e a utilização de 3,0\% de sacarose promoveu maior teor de clorofila total durante a fase de aclimatização ex vitro. Entretanto, o suprimento de $1,5 \%$ ou $3,0 \%$ de sacarose nos meios de cultura não promoveu diferenças significativas nas concentrações de proteínas totais das plantas durante a aclimatização (Tabela 4).

Tabela 2. Teor de clorofila total $\left(\mu \mathrm{g} . \mathrm{mg}^{-1}\right.$ de massa seca) e de proteínas ( $\mu \mathrm{g} \mathrm{mg}^{-1}$ de massa seca) em plantas de Epidendrun fulgens crescidos em meio de MS, adicionado ou não de reguladores de crescimento (RC), durante a fase de enraizamento in vitro (n=7)

Table 2. Total chlorophyl ( $\mu \mathrm{g} . \mathrm{mg}^{-1}$ of dry matter) and protein ( $\mu \mathrm{g} . \mathrm{mg}^{-1}$ of dry matter) in plants of Epidendrun fulgens grown in MS medium, with or without growth regulators addition $(C R)$ during an in vitro rooting period $(n=7)$

\begin{tabular}{|c|c|c|c|c|c|}
\hline \multirow{3}{*}{ TRATAMENTO } & \multirow{2}{*}{\multicolumn{2}{|c|}{$\frac{\text { CLOROFILA TOTAL }}{\text { TEMPO (DIAS) }}$}} & \multicolumn{3}{|c|}{ PROTEÍNAS } \\
\hline & & & \multicolumn{3}{|c|}{ TEMPO (DIAS) } \\
\hline & 0 & 60 & 0 & 60 & \\
\hline T1 (MS 33\% 1,5\% SACAROSE S/RC) & 93,56 & $219,21 \mathrm{~A}$ & 8,59 & 21,34 & $\mathrm{BCD}$ \\
\hline T2 (MS 33\% 3,0\% SACAROSE S/RC) & 93,56 & $178,49 \quad$ B & 8,59 & 13,66 & $\mathrm{E}$ \\
\hline T3 (MS 50\% 1,5\% SACAROSE S/RC) & 93,56 & $126,37 \mathrm{E}$ & 8,59 & 20,21 & $\mathrm{DE}$ \\
\hline T4 (MS 50\% 3,0\% SACAROSE S/RC) & 93,56 & $186,21 \mathrm{BC}$ & 8,59 & 21,05 & $\mathrm{CD}$ \\
\hline T5 (MS 33\% 1,5\% SACAROSE C/RC) & 93,56 & $109,31 \mathrm{~F}$ & 8,59 & 24,29 & $\mathrm{BCD}$ \\
\hline T6 (MS 33\% 3,0\% SACAROSE C/RC) & 93,56 & $126,92 \mathrm{E}$ & 8,59 & 29,40 & A \\
\hline T7 (MS 50\% 1,5\% SACAROSE C/RC) & 93,56 & $153,80 \mathrm{CD}$ & 8,59 & 28,43 & $\mathrm{AB}$ \\
\hline T8 (MS 50\% 3,0\% SACAROSE C/RC) & 93,56 & $145,19 \mathrm{D}$ & 8,59 & 27,48 & $\mathrm{ABC}$ \\
\hline
\end{tabular}

As médias seguidas da mesma letra na coluna não diferem entre si pelo teste de Tukey $(\mathrm{p}<0,05)$.

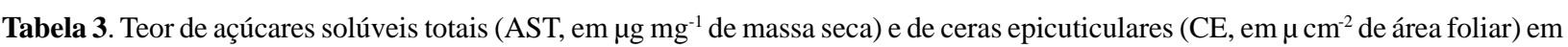
plantas de Epidendrun fulgens crescidas em meio MS adicionado ou não de regulador de crescimento (RC) durante a fase de enraizamento in vitro $(\mathrm{n}=7)$

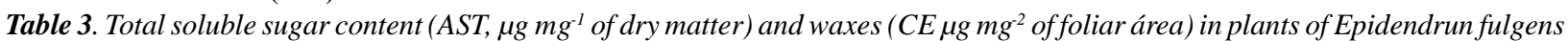
grown in SM medium with or without of growth regulators $(C R)$ addition during an in vitro rooting period $(n=7)$

\begin{tabular}{|c|c|c|c|c|c|c|c|}
\hline \multirow{3}{*}{ TR ATAMENTO } & \multicolumn{3}{|c|}{ AST } & \multicolumn{2}{|c|}{ AMIDO } & \multicolumn{2}{|c|}{$\mathrm{CE}$} \\
\hline & TEMP & (DIAS & & TEMPO & (DIAS) & TEMP & (DIAS) \\
\hline & 0 & 60 & & 0 & 60 & 0 & 60 \\
\hline T1 (MS 33\% 1,5\% SACAROSE S/RC) & 181,24 & 212,05 & B & 145,85 & $30,34 \mathrm{D}$ & 19,99 & $2,99 \mathrm{~B}$ \\
\hline T2 (MS 33\% 3,0\% SACAROSE S/RC) & 181,24 & 369,25 & $\mathrm{AB}$ & 145,85 & $23,66 \mathrm{D}$ & 19,99 & $3,84 \mathrm{~A}$ \\
\hline T3 (MS 50\% 1,5\% SACAROSE S/RC) & 181,24 & 200,97 & B & 145,85 & * & 19,99 & $0,85 \mathrm{CD}$ \\
\hline T4 (MS 50\% 3,0\% SACAROSE S/RC) & 181,24 & 285,55 & $A B$ & 145,85 & * & 19,99 & $1,46 \mathrm{C}$ \\
\hline T5 (MS 33\% 1,5\% SACAROSE C/RC) & 181,24 & 237,93 & B & 145,85 & 43,29 & 19,99 & $0,78 \mathrm{CD}$ \\
\hline T6 (MS 33\% 3,0\% SACAROSE C/RC) & 181,24 & 380,74 & $\mathrm{AB}$ & 145,85 & $10,99 \mathrm{E}$ & 19,99 & $1,36 \mathrm{CD}$ \\
\hline T7 (MS 50\% 1,5\% SACAROSE C/RC) & 181,24 & 568,43 & A & 145,85 & $96,28 \mathrm{~A}$ & 19,99 & $0,85 \mathrm{CD}$ \\
\hline T8 (MS 50\% 3,0\% SACAROSE C/RC) & 181,24 & 134,16 & B & 145,85 & $61,89 \mathrm{~B}$ & 19,99 & $0,70 \mathrm{D}$ \\
\hline
\end{tabular}

As médias seguidas de mesma letra não diferem entre si pelo teste de Tukey $(\mathrm{p}<0,05)$.

* Tratamento perdido. 
As condições da cultura in vitro tais como a baixa irradiância, a temperatura controlada e a alta umidade relativa do ar induzem uma baixa biossíntese e deposição de ceras nas plantas (CAMPOSTRINI e OTONI, 1996; TOMBOLATO e COSTA, 1998; KOZAI e KUBOTA, 2001; ERIG e SCHUCK, 2005). Entretanto, as plantas de E. fulgens cultivadas in vitro tiveram maiores teores de ceras totais quando comparadas às plantas aclimatizadas (Tabela 5). Os maiores teores de ceras epicuticulares encontrados nas folhas das plantas in vitro pode significar que tinham metabolismo mixotrófico.

Os níveis de sacarose de 1,5 e 3,0\% promoveram diferenças significativas nos teores de açúcares solúveis totais. Entretanto, o mesmo efeito não foi observado nos teores de ceras epicuticulares.

As plantas cultivadas em meios de culturas com redução na concentração de nutrientes e de sacarose, com ou sem RC, na fase de enraizamento in vitro, tiveram resultados que evidenciam um metabolismo mixotrófico aos 60 dias. Por outro lado, a transferência das plântulas para a aclimatização em telado de sombrite e câmara úmida parece ter induzido, aos 15 dias, tendência maior à autotrofia das plantas. Esse fato pode ser atribuído ao menor estresse das plantas nas novas condições ambientais. Portanto, o processo de pré-aclimatização de plantas in vitro, utilizando meios de cultura com redução de sais e sacarose, no sistema de micropropagação heterotrófica, contribui de forma significativa para o processo da aclimatização, com conseqüente diminuição do custo da muda micropropagada, uma vez que pode diminuir as perdas por morte e o tempo para a aclimatização. $\mathrm{O}$ controle do ambiente in vitro, meio de cultura e atmosfera do frasco, pode determinar práticas que promovam maior fotossíntese e desenvolvimento durante a fase in vitro e menor estresse e maior sobrevivência das plantas durante a aclimatização.

\section{CONCLUSÕES}

A redução da concentração de sais do meio de cultura de MS promoveu maior crescimento in vitro das plântulas de E. fulgens.

As alterações bioquímicas e fisiológicas das plântulas de E. fulgens cultivadas in vitro evidenciaram maior mixotrofia ao final dos 60 dias de cultivo in vitro.

A aclimatização das plântulas, provenientes dos meios com 3,0\% de sacarose, resultou em menor estresse evidenciado pelos teores de clorofila total e açúcares solúveis totais.

O sucesso da aclimatização das plântulas também depende das condições ambientais impostas na fase in vitro, para a redução do estresse da condição heterotrófica e/ou, mixotrófica à autotrófica.

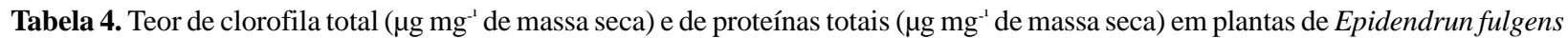
durante a fase de aclimatização ex vitro $(\mathrm{n}=7)$

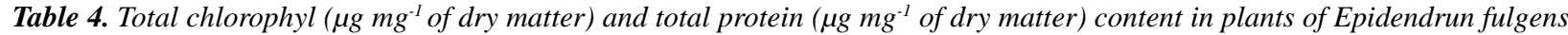
during an ex vitro acclimatization period $(n=7)$

\begin{tabular}{|c|c|c|c|c|}
\hline \multirow{3}{*}{$\begin{array}{l}\text { Tratamento } \\
\text { Sacarose (\%) }\end{array}$} & \multirow{3}{*}{$\begin{array}{c}\text { Clorofila total } \\
\text { Aclimatização (dias) } \\
0\end{array}$} & \multicolumn{2}{|c|}{ Proteínas } & \multirow[b]{3}{*}{15} \\
\hline & & Aclimatizaç & dias) & \\
\hline & & 15 & 0 & \\
\hline 1,5 & $159,04 \mathrm{~ns}$ & $231,44 \quad b$ & $22,63 \mathrm{~ns}$ & $24,19 \mathrm{~ns}$ \\
\hline 3,0 & $160,91 \mathrm{~ns}$ & $310,24 \mathrm{a}$ & $21,13 \mathrm{~ns}$ & $22,71 \mathrm{~ns}$ \\
\hline
\end{tabular}

as médias seguidas da mesma letra na coluna não diferem entre si pelo teste de Tukey $(\mathrm{p}<0,05)$ $\mathrm{ns}=$ valores não significativos pelo teste de Tukey $(\mathrm{p}<0,05)$

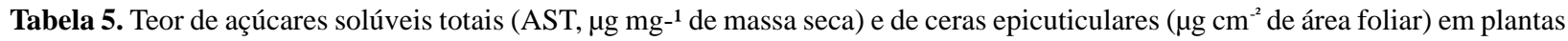
de Epidendrun fulgens durante a fase de aclimatização ex vitro $(\mathrm{n}=7)$

Table 5. Total soluble sugar content (AST, $\mu \mathrm{g} \mathrm{mg}^{-1}$ of dry matter) and over cuticle waxes ( $\mu \mathrm{g} \mathrm{mg}^{-2}$ of foliar área) in plants of Epidendrun fulgens grown in SM medium with or without of growth regulators (CR) addition during an ex vitro acclimatization period $(n=7)$

\begin{tabular}{ccccc}
\hline Tratamento & AST & \multicolumn{3}{c}{ Ceras epicuticulares } \\
Sacarose (\%) & Aclimatização (dias) & \multicolumn{2}{c}{ Aclimatização } & $($ dias) \\
\cline { 2 - 5 } & \multicolumn{1}{c}{0} & 15 & 0 & 15 \\
\hline 1,5 & $272,07 \mathrm{~ns}$ & $39,24 \mathrm{~b}$ & $1,55 \mathrm{~ns}$ & $0,90 \mathrm{~ns}$ \\
3,0 & $304,08 \mathrm{~ns}$ & $190,75 \mathrm{a}$ & $2,11 \mathrm{~ns}$ & $0,66 \mathrm{~ns}$ \\
\hline
\end{tabular}

as médias seguidas da mesma letra na coluna não diferem entre si pelo teste de Tukey $(\mathrm{p}<0,05)$. $\mathrm{ns}=$ valores não significativos pelo teste de Tukey $(\mathrm{p}<0,05)$ 


\section{REFERÊNCIAS}

BRADFORD, M.M. A rapid and sensitive method for the quantitation of microgram quantities of protein utilizing the principle of protein- dye binding. Analytical Biochemistry, New York, v. 72, p. 248-254, 1976.

CALDAS, L.S.; FERREIRA, M.E. Meios nutritivos. In: TORRES, A.C.; CALDAS, L.S.; BUSO, J.A. Cultura de tecidos e transformação genética de plantas. Brasília: Embrapa-CNPH, 1998. v.1, p.187-132.

CALVETE, E.O.; KAMPF, A. N.; SUZIN, M. Concentração de sacarose no enraizamento in vitro de morangueiro. Horticultura brasileira, Botucatu, v.20, n.2 , p.186-191, junho, 2002.

CAMPOSTRINI, E.; OTONI, W.C. Aclimatação de plantas: abordagens recentes. Associação Brasileira de Cultura de Plantas, Brasília/CNPH, n 25, p. 1-9, setembro. 1996.

CENTELLAS, A.Q.; FORTES, G.R.L.; MÜLLER, N.T.G.; ZANOL, G.C.; FLORES, R.; GOTTINARI, R.A. Efeito das auxinas sintéticas no enraizamento in vitro da macieira. Pesquisa Agropecuária Brasileira, Brasília, v 34, n.2, p.181186, 1999.

CHEN, J.G. Dual auxin signaling pathways control cell elongation and division. Journal of Plant Growth Regulation, Berlin-Alemanha Ocidental, v. 20, p. 255-264, 2001.

ERIG, A.C.; SCHUCH, M.W. Micropropagação fotoautotrófica e uso da luz natural. Ciência Rural, Santa Maria, v 35, n 4, p.961-965, julho-agosto. 2005.

GEORGE, E.F. Plant Propagation by Tissue Culture. $2^{\text {nd }}$. ed. Eversley: Exegetics, 1996. v.2, 1361p.

GRATTAPAGLIA, D.; MACHADO, M.A. Micropropagação. In: TORRES, A.C.; CALDAS, L.S.; BUSO, J.A.(Ed.). Cultura de tecidos e transformação genética de plantas. Brasília: EMBRAPA-CBAB, 1998. v.1, p.183-260.

GROUT, B.W.W.; ASTON, H. Transplanting of cauliflower plants regenerated from meristem culture. II. Carbon dioxide fixation and the development of photosyntetic ability. Horticultural Research, Edinburgh-Escocia, v.17, p.65-77, 1977.

KNUDSON, L. A new nutrient solution for germination of orchid seed. American Orchid Society Bulletin, Cambridge, v. 15, p.214-217, 1946.

KOZAI, T.; KUBOTA, C. Developing a photoautotrophic micropropagation system for woody plants. Journal of Plant Research, Tokyo-Japan, v. 114, p. 525-537, 2001.

KOZAI, T.; NGUYEN, Q.T. Photoautotrophic micropropagation of woody and tropical plants. In: JAIN, S.M.; ISHII, K. Micropropagation of woody trees and fruits. Dordrecht: Kluwer Academic, 2003. p.757-781.

KUBOTA, C.; KOZAI, T. Growth and net photosynthetic rate of salanum tuberosum in vitro under forced and natural ventilation. HortScience, Alexandria, v.27, p.1312-1314, 1992.
LEYSER, O.; BERLETH, T. A molecular basis for auxin action. Cell \& Developmental Biology, Palo Alto CA, v. 10, p. 131-137, 1999.

LICHTENTHALER, H.K. Chlorophylls and carotenoids: pigments of photsynthetic biomembranes. In: Methods in enzymology. San Diego: Academic Press, 1987. v.148, p.350-382.

McCOMB, J.A.; BENNETT, I.J. Eucalypts (Eucalytus spp). In: BAJAJ, Y.P.S. Biotechnology in agriculture and forestry. Berlin: Springer - Verlag, 1985. p.341362.

McCREADY, R.M.; GUGGLOZ, J.; SILVEIRA, V.; OWENS, H.S. Determination of starch and amylose in vegetables. Analytical Chemistry, Washington, v. 22, p. 1156-1158, 1950.

MURASHIGE, T.; SKOOG, F. A revised medium for rapid growth and bioassays with tabacco tissue cultures. Physiologia Plantarum, Copenhagen, v. 15, n. 3, p.473-497, 1962.

RANDI, A.M.; FELIPPE, G.M. Mobilization of storage reserves during Chyathea delgadii spore germination. The Botanical Magazine, Tokyo-Japan, v.101, n.1064 ,p.529-550, 1988.

ROBERTS, A.V.; SMITH, E. F.; MOTTLEY, J. The Preparation of micropropagated plantlets for transfer to soil without acclimatization. Plant Cell and Tissue Culture, Hague-Holanda, v.6, n.3, p. 227-236, 1990.

SOUZA, B.M.; KRAUS, J.E.; ENDRES, L.; MERCIER, $H$. Relationships between endogenous hormonal levels and axillary bud development of Ananas comosus nodal segments. Plant Physiology and Biochemistry, Paris, v.41, n.8, p.733-739, 2003.

SHANNON, J.C. A procedure for the extraction and fractionation of carbohydrates from immature Zea mays kernels. Research Bulletin, Wisconsin, v. 842, p.1-8, 1968.

TAIZ, L.; ZEIGER, E. Fisiologia vegetal. 3.ed. Porto Alegre: Artmed, 2004. 719p. il.

TOMBOLATO, A.F.C.; COSTA, A.M.N. Micropropagação de plantas ornamentais. Campinas: Instituto Agronômico, 1998. 72p.

TORRES, A.C.; CALDAS, L.S.; BUSO, J.A. Cultura de tecidos e transformação genética de plantas. Brasília: EMBRAPA-CNPH, 1979. 2v.

UMBREIT, W.W.; BURRIS, R. H. Method for glucose and others sugars. 4.ed. In: UMBREIT, W.W.; BURRIS, R.H.; STAUFFER, J.P. (Ed.) Manometric techniques: a manual describing methods applicable to the study of tissue metabolism. 4.ed. Minneapolis: Burgess, 1964.305p.

VAN HUYLENBROECK, J. M.; DEBERGH, P.C. Monitoring quality of micropropagated plants during acclimatization. Acta Horticulturae, Wageningen v. 517, p.65-72, 2000. 